\title{
Priorities in labor motivation of young agricultural scientists
}

\author{
Yuri Pichugin ${ }^{1}$, Yuri Lobeyko ${ }^{2}$, Elena Zritneva ${ }^{2}$, Valentine Ivashova ${ }^{3,}$, and Bulat Pashtaev ${ }^{4}$ \\ ${ }^{1}$ Saint-Petersburg State University of Aerospace Instrumentation, 67, Bolshaya Morskaya St., Saint \\ Petersburg, 190000, Russia \\ ${ }^{2}$ North Caucasus Federal University, 1, Pushkin Str., Stavropol, 355017, Russia \\ ${ }^{3}$ Stavropol State Agrarian University, 12, Zootechnicheskiy lane, Stavropol, 355017, Russia \\ ${ }^{4}$ Dagestan State Agrarian University, 180, Magomed Gadzhiev st., Makhachkala, 367032, Russia
}

\begin{abstract}
The article presents the results of the study of priorities in the field of labor motivation of young agricultural scientists. A review of publications on labor motivation shows that important areas of research are the definition of priorities among internal and external motives and their study in segmentation by age and spheres of activity. Therefore, the determination of the priorities of labor motivation of young agricultural scientists is of great scientific and practical interest. We studied the motives of effective research and teaching activities of young employees on the example of a sociological survey conducted on the basis of Stavropol State Agrarian University. Using SPSS Statistics (version 21) software package and a unique mathematical apparatus, the priorities of labor motivation of young agricultural scientists were established. From the point of view of theoretical significance, the presented materials make it possible to use the research algorithm in such situations. The practical significance of the research results lies in the formation of an information base for strategic management of personnel processes in organizations of agricultural education.
\end{abstract}

\section{Introduction}

Many studies have been devoted to the issues of labor motivation of employees [1-5]. The results of proven approaches to the study and optimization of work motivation can have a positive effect on the efficiency of work processes in an organization [6-9]. At the same time, changing working conditions, goals and objectives of professional and production activities, technical and technological innovations require updating the priorities of labor motivation. In addition, labor motivation varies greatly depending on the field of activity and the category of employees in terms of age, educational, socio-psychological and other significant characteristics. Thus, we see how wide the research field of work motivation is $[10,11]$.

A special specificity of labor motivation exists, in our opinion, in research activities, which are associated with creative search. The planning and rationing of this activity is

\footnotetext{
*Corresponding author: vivashov@mail.ru
} 
complex. There are high risks of obtaining negative results of research search, which have a negative effect on labor motivation. At the same time, a correctly built motivational field of research activity significantly brings the positive results of work closer.

Researchers A.U. Ogorodnikov, E.U. Ruppel in the article presented the results of studying the institutional possibilities and limitations of the professional self-realization of researchers in the context of the innovative restructuring of Russian science [12]. They developed and tested a three-level model for assessing the ratio of systemic, organizational and personal factors in the disclosure of the intellectual potential of a scientist. In the course of analyzing the results of the federal survey, they established contradiction between the personal motivation of scientists and the mechanisms that regulate the work of scientific organizations. According to the research results, the motivational field of Russian scientists includes such components as the desire for professional self-realization and active scientific research, personal and social responsibility, awareness of the social significance of their research and the desire to be a member of a successful team. Among the identified areas for improvement are named: optimization of professional communications of scientists with industrial enterprises and government agencies; expanding participation in the world scientific discourse; enhancing opportunities for interdisciplinary research. In addition, the researchers point to the need to involve the expert scientific community in the development of criteria and indicators of scientific activity. It is participation in determining the criteria for the productivity of scientific activity that can serve as a catalyst for the motivational process. These are important conclusions for understanding the priorities in the labor motivation of young agricultural scientists. For the development of approaches to the study of labor motivation of young agricultural scientists, we see important conclusions. First, the model takes into account both internal and external motives of the professional activity of scientists. The second, it is named a list of established motives of professional activity of scientists that are relevant for a given period of time. The third, it is identified the problems that reduce the effectiveness of scientific activities. At the same time, we consider age to be a significant sign that will show different priorities of labor motivation depending on belonging to a particular group. In addition, it is useful from the point of view of the practical application of research results in the development of management decisions is ranking the priority of the identified motives with the definition of the key one.

For modern researchers in the agricultural sector, the practical vector of this activity and the solution of specific production problems with real economic benefits are important. Study authors Tariq Ahmed, V.G.R. Chandran, Jane E. Klobas, Francisco Liñán, Panagiotis Kokkalisf show that business performance directly depends on knowledge, inspiration and resources [13].

Researchers C. Fischer, C.P. Malycha, E. Schafmann show the influence of internal motivation and synergistic external motivators on the effectiveness of creativity and innovation [14]. In the course of analyzing the results of a survey conducted among employees of an international consulting company, it was found that a complex system of external motivators stimulates internal motivation and has a positive effect on the creative and innovative performance of employees. We see that an organization's reward system stimulates the creativity of knowledge workers. This is an important conclusion for the study of the labor motivation of young agricultural scientists.

Authors R.M. Ryan, E.L. Deci emphasize that with all the study of motivation issues, the changing realities of the external environment put forward new directions in the study of external stimuli of human activity. According to the authors, intrinsic motivation remains a relatively stable construct that reflects the natural human tendency to learn and assimilate [15]. As for external stimuli, they undergo more significant changes, but, nevertheless, they can be grouped into two autonomous clusters - either external control or true selfregulation. In the article, the authors examine the relationship of these clusters with the 
basic human needs for autonomy, competence and social relations. For our study, it is important to determine the strategic priority in the external motivation of young agricultural scientists for self-regulation, which is quite correlated with the conclusions about the need for their participation in determining the criteria for the productivity of scientific activity.

The quality of the university ecosystem plays an important role in stimulating the innovative creativity of scientists. According to W. Yuqiu, the university innovation ecosystem contributes to the involvement of young people at the stage of study in interdisciplinary research and programs, student unions of entrepreneurs, introduces the work of patent transfer offices, subsidiaries connecting knowledge and innovation [16]. Thus, the foundations of professional and labor motivation of young scientists are laid even during the period of study [17].

Based on the review of publications on labor motivation, it can be said that important areas of research are the definition of priorities among internal and external motives and their study in segmentation by age and areas of activity. Therefore, the determination of the priorities of labor motivation of young agricultural scientists is of great scientific and practical interest.

\section{Materials and methods}

The study of the motivational field of young agricultural scientists was carried out on the basis of Stavropol State Agrarian University by the method of individual questionnaires. A total of 95 people took part in the survey. The database is generated in the statistical package SPSS Statistics (version 21). In the course of the study, respondents from among young agricultural scientists expressed their attitude to 19 factors of job satisfaction. Among them, interest in work; achievement of professional success; relationships with colleagues in the team; material remuneration for work; correspondence of official position to abilities; the ability to learn something new; growth of professional knowledge; respect for the team; the ability to perform all the assigned work; management approval; performing low-skilled work; getting pleasure from work; labor organization; disagreements at work; rewards for work; desire to change jobs due to dissatisfaction with remuneration; misunderstanding on the part of the head; working conditions; achieving professional goals. The respondent assessed the manifestation of each factor on a scale from -5 to +5 , where -5 - the factor does not appear; $+5-$ the factor manifests itself as much as possible.

\subsection{Principal component regression model}

The initial data can be represented as the matrix $\mathbf{Y}$ of dimension $m \times n$, where $m=19$ is the number of questions, and $n=95$ is the number of respondents. We will denote the elements of this matrix by $y_{i j}(i=1,2, \ldots, m ; j=1,2, \ldots, n)$. Based on these data, using the SPSS Statistics statistical package, the correlation matrix $\mathbf{R}$ of dimension $m \times m$ and the orthogonal matrix $\mathbf{Q}$ of dimension $m \times m$ are calculated, which transforms the matrix to a diagonal form. Thus, the equality is

$$
\mathbf{Q}^{T} \mathbf{R Q}=\Lambda=\operatorname{diag}\left(\lambda_{1}, \lambda_{2}, \ldots, \lambda_{m}\right),
$$

in condition that the spectrum is ordered in decreasing order $\lambda_{1} \geq \lambda_{2} \geq \ldots \geq \lambda_{m}$, where $T$ is the transposition operator. SPSS Statistics automatically selected the first $k(k=5)$ spectral values (the main part of the spectrum), which correspond to the first $k$ columns of the matrix Q. Table 1 shows the spectrum (2nd column) and the first five columns of the 
orthogonal matrix $\mathbf{Q}$ (from $3 \mathrm{~d}$ to 7 th columns of table 1). The main part of the spectrum is shown in bold

Table 1. Spectrum of the matrix R and the first 5 columns of the matrix Q.

\begin{tabular}{|c|c|c|c|c|c|c|}
\hline No & Spectrum of R & \multicolumn{7}{|c|}{ The first 5 columns of the matrix Q } \\
\hline 1 & 6.207 & 0.314 & 0.112 & 0.045 & 0.087 & 0.135 \\
\hline 2 & 2.187 & 0.226 & 0.121 & -0.371 & -0.100 & -0.124 \\
\hline 3 & 1.601 & 0.296 & -0.158 & 0.074 & 0.242 & 0.280 \\
\hline 4 & 1.366 & 0.177 & 0.090 & 0.264 & -0.472 & 0.389 \\
\hline 5 & 1.07 & -0.190 & 0.212 & 0.232 & -0.083 & -0.134 \\
\hline 6 & 0.88 & 0.154 & 0.221 & 0.423 & -0.175 & -0.203 \\
\hline 7 & 0.8 & 0.252 & 0.130 & -0.163 & 0.068 & -0.144 \\
\hline 8 & 0.75 & 0.297 & -0.010 & 0.064 & 0.325 & 0.147 \\
\hline 9 & 0.719 & -0.048 & 0.335 & 0.312 & 0.384 & -0.192 \\
\hline 10 & 0.647 & 0.170 & 0.235 & -0.288 & 0.105 & -0.077 \\
\hline 11 & 0.582 & 0.149 & 0.371 & -0.375 & -0.027 & -0.057 \\
\hline 12 & 0.47 & 0.313 & 0.083 & 0.319 & 0.027 & -0.066 \\
\hline 13 & 0.412 & -0.204 & 0.229 & -0.058 & 0.101 & 0.588 \\
\hline 14 & 0.35 & -0.152 & 0.436 & -0.047 & 0.036 & -0.170 \\
\hline 15 & 0.281 & -0.179 & 0.322 & 0.159 & 0.262 & 0.040 \\
\hline 16 & 0.245 & 0.188 & 0.257 & 0.045 & -0.524 & -0.006 \\
\hline 17 & 0.204 & -0.220 & 0.313 & -0.124 & -0.026 & 0.426 \\
\hline 18 & 0.14 & 0.322 & 0.034 & 0.144 & 0.195 & 0.164 \\
\hline 19 & 0.089 & 0.288 & 0.071 & -0.175 & 0.012 & 0.031 \\
\hline
\end{tabular}

We will consider the columns of the input data of the matrix $\mathbf{Y}$ as realizations of a random vector $\mathbf{y}$ of dimension $m$. In this case, all values of the matrix $\mathbf{Y}$ (vector $\mathbf{y}$ ) are transformed by means of centering and normalization operations: $y_{i j}:=\left(y_{i j}-\bar{y}_{i}\right) / \sigma_{i}$, where $\bar{y}_{i}$ is the average mean and $\sigma_{i}$ is the standard deviation, calculated from the values of $i$ row of the original matrix $\mathbf{Y}$. In the situation under consideration, the transformed vector $\mathbf{y}$ has the model

$$
\mathbf{y}=\mathbf{P z}+\varepsilon
$$

where $\mathbf{P}$ is the matrix of dimension $m \times k$, consisting of the first $k$ columns of $\mathbf{Q}$; $\mathbf{z}$ is the vector of principal components of dimension $k ; \boldsymbol{\varepsilon}$ is the vector of errors of the regression (1). The principal components (components of the vector $\mathbf{z}$ ) are independent of each other, and the mutual covariance matrix of the vector of principal components is equal to $\mathbf{V}_{\mathbf{z}}=$ $\operatorname{diag}\left(\lambda_{1}, \lambda_{2}, \ldots, \lambda_{k}\right)$. Usually, the principal components are interpreted as hidden causes (in our case, ulterior motives) in numerical terms. It is assumed that the components of the vector are also mutually independent, have zero mean and the same variation $\sigma^{2}$.

\subsection{Information Ordering Model}

Let $\mathbf{q}$ be a subset of the numbers of the components of the vector $\mathbf{y}$, i.e. $\mathbf{q} \subset\{1,2, \ldots, m\}$. Let $\mathbf{y}_{\mathbf{q}}$ be a vector with components of the vector $\mathbf{y}$ whose numbers are contained in $\mathbf{q}$, and $\mathbf{P}_{\mathbf{q}}$ is a matrix containing only those rows of the matrix $\mathbf{P}$ whose numbers are contained in q. Then the amount of information according to Shannon's Theory contained in the vector $\mathbf{y}_{\mathbf{q}}$ with respect to the principal components (ulterior motives) is (see [1])

$$
I\left(\mathbf{y}_{\mathbf{q}}, \mathbf{z}\right)=\frac{1}{2} \log _{a} \operatorname{det}\left(\mathbf{I}+\sigma^{-2} \mathbf{P}_{\mathbf{q}}^{T} \mathbf{P}_{\mathbf{q}} \mathbf{V}_{\mathbf{z}}\right)
$$


where I is the identity matrix; $a>1$ sets the scale of information units; detis is an operation of calculating the determinant of a matrix. A biased estimate is used as $\sigma^{2}$ when calculating the amount of information (see [18] and [19])

$$
\sigma^{2}=\frac{1}{m-k} \sum_{i=k+1}^{m} \lambda_{i} .
$$

The number of elements $\mathbf{q}$ is usually denoted by cardq. Increasing cardq from zero to $m$ and maximizing $I\left(\mathbf{y}_{\mathbf{q}}, \mathbf{z}\right)$ at every selection step, we get an increasing sequence of values of the amount of information $I_{j}(j=1,2, \ldots, m)$. It is convenient to consider this sequence in relative values, excluding the dependence on the choice of the base of the logarithm $a$, transforming according to the rule $I_{j}:=\left(I_{j} / I_{m}\right) 100 \%$, where $I_{m}=I(\mathbf{y}, \mathbf{z})$ is the total amount of information. In this case, we will receive a sequence of numbers of questions (and, consequently, a sequence of questions) in descending order of their informational value regarding ulterior motives

Comment. Instead of model (1), we can consider a factor model of the form

$$
\mathbf{y}=\mathbf{L f}+\varepsilon,
$$

where $\mathbf{L}$ is a matrix of factorial loads of dimension $m \times k$; $\mathbf{f}$ is a vector of hidden factors of dimension $k$. The vector $\varepsilon$ remains the same, as does the biased estimate $\sigma^{2}$. When using model (3) instead of formula (2), we will have the formula

$$
I\left(\mathbf{y}_{\mathbf{q}}, \mathbf{f}\right)=\frac{1}{2} \log _{a} \operatorname{det}\left(\mathbf{I}+\sigma^{-2} \mathbf{L}_{\mathbf{q}}^{T} \mathbf{L}_{\mathbf{q}} \mathbf{V}_{\mathbf{f}}\right)
$$

$\mathbf{L}_{\mathbf{q}}$ is a matrix containing only those rows of the matrix $\mathbf{L}$ whose numbers are contained in $\mathbf{q} ; \mathbf{V}_{\mathbf{f}}$ is the cross-covariance matrix of factors. In this case, the final result of informational ordering will not change, since information according to Shannon's Theory is invariant to linear transformations (see [1]), which take place when passing from model (2) to model (3).

\section{Results and discussion}

\subsection{Information Ordering Results}

The information ordering technique described above is not implemented in SPSS Statistics. Therefore, all subsequent calculations were performed in Excel. Table 2 shows the results of the information ordering. Nevertheless, it seems advisable to visually examine the third and fourth columns of this table, presenting them graphically. So Fig. 1 shows a sequential increase in the relative amount of information with sequential selection. Fig. 1 shows that starting from the 7 th step, the intensity of growth in the amount of information significantly decreases.

The latter is better seen in Fig. 2, which shows the decrease in the increments of the amount of information with sequential information selection. In table 2 , in the second column, the numbers of the first 6 questions are highlighted in bold, giving approximately $60 \%$ of the relative information about latent motivation. The value of the ratio of two successive increments of the amount of information is highlighted in bold in the fifth column of the table. This minimum value, equal to 0.67 , corresponds to a significant decrease in the increments in the amount of information, starting from the 7th step of the sequential selection. 
Table 2. Results of information ordering.

\begin{tabular}{|c|c|c|c|c|}
\hline $\begin{array}{c}\text { Number } \\
\text { of the } \\
\text { selection } \\
\text { step }(\boldsymbol{j})\end{array}$ & $\begin{array}{c}\text { The number } \\
\text { of the } \\
\text { question }\end{array}$ & $\begin{array}{c}\text { Quantity of } \\
\text { information } \\
\boldsymbol{I}_{\mathbf{j}(\boldsymbol{\%})}\end{array}$ & $\begin{array}{c}\text { Increase the } \\
\text { amount of } \\
\text { information } \\
\boldsymbol{\Delta} \boldsymbol{I}_{\mathbf{i}} \mathbf{( \% )}\end{array}$ & $\begin{array}{c}\text { The ratio of } \\
\text { increments of the } \\
\text { amount of } \\
\text { information } \\
\boldsymbol{\Delta}_{\boldsymbol{j}+\boldsymbol{1}} / \boldsymbol{\Delta}_{\boldsymbol{j}}\end{array}$ \\
\hline 1 & $\mathbf{1 2}$ & 11.74 & 11.74 & 0.88 \\
\hline 2 & $\mathbf{1 1}$ & 22.03 & 10.28 & 0.99 \\
\hline 3 & $\mathbf{9}$ & 32.22 & 10.19 & 0.95 \\
\hline 4 & $\mathbf{1 3}$ & 41.86 & 9.64 & 0.96 \\
\hline 5 & $\mathbf{4}$ & 51.09 & 9.23 & 0.91 \\
\hline 6 & $\mathbf{3}$ & 59.47 & 8.38 & $\mathbf{0 . 6 7}$ \\
\hline 7 & 16 & 65.05 & 5.58 & 0.82 \\
\hline 8 & 17 & 69.65 & 4.59 & 0.94 \\
\hline 9 & 8 & 73.96 & 4.31 & 0.96 \\
\hline 10 & 2 & 78.10 & 4.14 & 0.97 \\
\hline 11 & 6 & 82.11 & 4.01 & 0.88 \\
\hline 12 & 14 & 85.63 & 3.51 & 0.78 \\
\hline 13 & 18 & 88.38 & 2.75 & 0.98 \\
\hline 14 & 15 & 91.06 & 2.69 & 0.93 \\
\hline 15 & 10 & 93.55 & 2.49 & 0.73 \\
\hline 16 & 5 & 95.37 & 1.82 & 0.97 \\
\hline 17 & 1 & 97.14 & 1.77 & 0.87 \\
\hline 18 & 7 & 98.68 & 1.54 & 0.86 \\
\hline 19 & 19 & 100.00 & 1.32 & \\
\hline
\end{tabular}

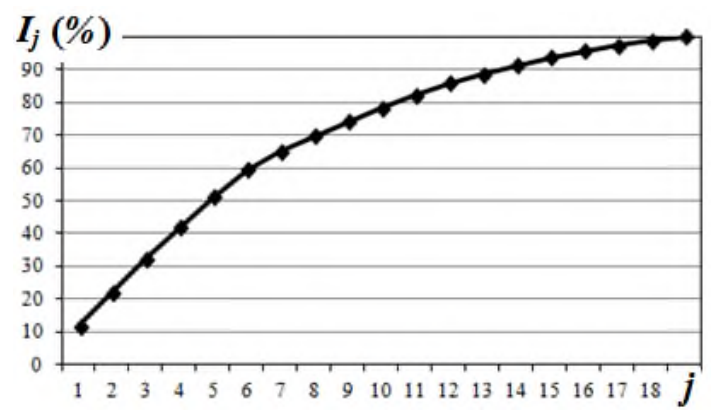

Fig. 1. Increase in the amount of information in the process of sequential selection of questions.

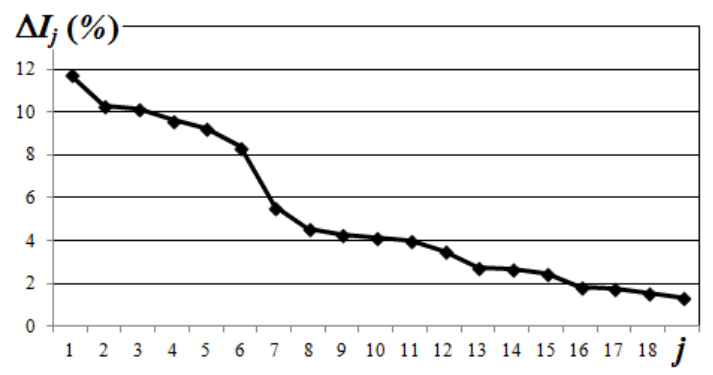

Fig.2. Decrease of increments in the amount of information in the process of sequential selection of questions.

The priorities of the labor motivation of young scientists in the agricultural sector were distributed in such a way that the inner motive is in the first place - the work process is enjoyable. Interaction in the educational process with students who are the most active, educated part of young people in any society, the ability to conduct independent research, 
participate in university projects under the guidance of leading scientists, and solve scientific and practical problems.

\section{Conclusion}

Young agricultural scientists, putting the pleasure they get from work in the first place among labor motives, are largely ready to put up with the role of "apprentices", performing large volumes of technical work with which they cannot always cope. It was also found that moral incentives at the start of the professional career of an agricultural scientist play a more significant role than material reward. And the point of growth in improving the system of motivation for young scientists in the agricultural sector is the organization of work in general and individual labor processes. Only rigorous mathematical methods and models can ensure the objectivity of the sociological conclusions of the research.

\section{References}

1. S. Johari, K. N. Jha Journal of Management in Engineering, 36(5), 04020052 (2020)

2. M. Nikolova, F. Cnossen Labour Economics, 65, 101847 (2020)

3. T. Gaponenko, S. Muradova, V. Litvinova E3S Web of Conferences, 175, 15003 (2020)

4. I. Abakumova, A. Kukulyar, A. Kolenova E3S Web of Conferences, 175, 15009 (2020)

5. S. V. Novikov, E. R. Chernova, I. A. Kulkova Quality - Access to Success, 21(176), 22-26 (2020)

6. V. Hiller, N. Raffin Journal of Economic Behavior and Organization, 174, 131-149 (2020)

7. S. Miao, J. Rhee, I. Jun Sustainability (Switzerland), 12(9), 36-30 (2020)

8. J Kukreja Test Engineering and Management, 83, 9850-9855 (2020)

9. V. N. Shcherbakov, A. V. Dubrovsky, I. V. Makarova International Journal of Management, 11(4), 272-281 (2020)

10. I. Khlivna, O. Kartashova, V. Filippova International Journal of Management, 11(4), 339-349 (2020)

11. V. Ivashova,G. Tokareva, E. Agalarova IOP Conference Series: Materials Science and Engineering, 775 (1), 012020 (2020)

12. A. U. Ogorodnikov, E. U. Ruppel Obrazovanie I Nauka, 21(8), 130-163 (2019)

13. Tariq Ahmed, V. G. R. Chandran, J. E. Klobas The International Journal of Management Education, 18 (1), 100327 (2020)

14. C. Fischer, C. P. Malycha, Schafmann E 2019 Frontiers in Psychology, 10

15. R. M. Ryan, E. L. Deci Contemporary Educational Psychology, 25(1), 54-67 (2020)

16. W. Yuqiu Quality Education for Teenagers 120-126 (2006)

17. V. Goncharov, A. Erokhin, O. Kolosova IOP Conference Series: Earth and Environmental Science, 422 (1), 012127 (2020)

18. Yu. A. Pichugin St. Petersburg Polytechnical State University Journal. Physics and Mathematics, 12 (3), 164-176 (2019)

19. Yu. A. Pichugin St. Petersburg Polytechnical State University Journal. Physics and Mathematics, 11 (3), 74-89 (2018) 